\title{
THE EFFECT OF BASELINE METABOLIC RATE ON \\ PULMONARY O UPTAKE KINETICS DURING VERY HEAVY INTENSITY EXERCISE IN BOYS AND MEN
}

${ }^{1}$ Brynmor C. Breese, ${ }^{1}$ Alan R. Barker, ${ }^{1}$ Neil Armstrong, ${ }^{2}$ Andrew M. Jones and ${ }^{1}$ Craig A. Williams*

${ }^{1}$ Children's Health and Exercise Research Centre, ${ }^{2}$ Sport and Health Sciences, College of Life and Environmental Sciences, University of Exeter, UK.

Running Head: Muscle recruitment and $\dot{\mathrm{V}}_{\mathrm{O}_{2}}$ kinetics in children and adults

*Corresponding author:

Craig A Williams, Ph.D.

Children's Health and Exercise Research Centre, Sport and Health Sciences, University of Exeter, St Luke's Campus, Heavitree Road, Exeter, EX1 2LU, UK.

E-mail: C.A.Williams@exeter.ac.uk

Tel: +44 01392 264890; Fax: +4401392 724726 


\begin{abstract}
This study tested the hypothesis that pulmonary $\dot{\mathrm{V}}_{\mathrm{O}_{2}}$ kinetics would be slowed during 'work-to-work' exercise in adults but not in children. Eight boys (mean age $=12.5 \pm 0.5$ yr) and nine men completed very heavy step transitions initiated from either 'unloaded' pedalling $(\mathrm{U} \rightarrow \mathrm{VH})$ or unloaded-to-moderate cycling (i.e. $\mathrm{U} \rightarrow \mathrm{M}$ to $\mathrm{M} \rightarrow \mathrm{VH})$. The phase II $\tau$ was significantly $(p<0.05)$ lengthened in $M \rightarrow V H$ compared to $U \rightarrow M$ and $U \rightarrow V H$ in boys ( $30 \pm 5$ vs. $19 \pm 5$ vs. $21 \pm 5$ s) and men ( $49 \pm 14$ vs. $30 \pm 5$ vs. $34 \pm 8$ s). In $\mathrm{U} \rightarrow \mathrm{VH}$, a greater relative $\dot{\mathrm{V}}_{\mathrm{O}_{2}}$ slow component temporally coincided with an increased linear iEMG slope in men compared boys ( $\dot{\mathrm{V}}_{\mathrm{O}_{2}}$ slow component: $16 \pm 3$ vs. $11 \pm 4 \%$; iEMG slope: $0.19 \pm 0.24$ vs. $-0.06 \pm 0.14 \%, \mathrm{p}<0.05)$. These results suggest that an agelinked modulation of $\dot{\mathrm{V}}_{\mathrm{O}_{2}}$ kinetics might be influenced by alterations in muscle fibre recruitment following the onset of exercise.
\end{abstract}

Key words: phase II time constant, $\dot{\mathrm{V}}_{\mathrm{O}_{2}}$ slow component, electromyogram, youth. 


\section{Introduction}

Following the onset of step exercise, the arrival of hypoxic blood at the pulmonary capillaries heralds an exponential rise in pulmonary $\mathrm{O}_{2}$ uptake $\left(\dot{\mathrm{V}}_{\mathrm{O}_{2}}\right)$ that has been shown to reflect the kinetics of muscle $\mathrm{O}_{2}$ consumption $\left(\mathrm{mV}_{\mathrm{O}_{2}}\right)$ in humans (Krustrup, Jones, Wilkerson, Calbet, \& Bangsbo, 2009) and is reported to be speeded in children relative to adult or teenage counterparts [see Armstrong and Barker (2009) for a review]. Furthermore, there is an elevated $\mathrm{O}_{2}$ cost or 'gain' during the initial exponential phase that coincides with an attenuated slow rise in $\dot{\mathrm{V}}_{\mathrm{O}_{2}}$ above the primary phase amplitude (i.e. the $\dot{\mathrm{V}}_{\mathrm{O}_{2}}$ slow component) in young people exercising above the gas exchange threshold (GET) (Armon, Cooper, Flores, Zanconato, \& Barstow, 1991; Fawkner \& Armstrong, 2004; Williams, Carter, Jones, \& Doust, 2001). The physiological factors that mediate age differences in $\dot{\mathrm{V}}_{2}$ kinetics are unresolved with few experimental data available.

Previous studies have reported that step exercise transitions initiated from an elevated baseline work rate elicits a lengthened phase II time constant $(\tau)$ and increases the total $\dot{\mathrm{V}}_{\mathrm{O} 2}$ gain compared to metabolic transitions imposed from rest or 'unloaded' pedalling (Brittain, Rossiter, Kowalchuk, \& Whipp, 2001; Dimenna, Bailey, Vanhatalo, Chidnok, \& Jones, 2010; DiMenna, Wilkerson, Burnley, \& Jones, 2008; Hughson \& Morrissey, 1982; MacPhee, Shoemaker, Paterson, \& Kowalchuk, 2005; Wilkerson \& Jones, 2006, 2007). One interpretation, yet to be refuted, is that transitions to a higher metabolic rate preceded by a light bout of exercise might amplify the metabolic properties of higherorder (type IIa and IIx) motor units on the pulmonary $\mathrm{O}_{2}$ signal under these 
circumstances. Based on the assumption that higher-order (type II) muscle fibres have slower $\dot{\mathrm{V}}_{\mathrm{O}_{2}}$ kinetics and an increased metabolic cost per unit of force production (Crow \& Kushmerick, 1982; Krustrup, et al., 2008), differences in muscle fibre recruitment might therefore be linked to faster phase II $\dot{\mathrm{V}}_{\mathrm{O}_{2}}$ kinetics and a reduced $\dot{\mathrm{V}}_{\mathrm{O}_{2}}$ slow component in youth.

It has been proposed, at least in adults and more recently in teenagers (Breese, Armstrong, Barker, \& Williams, 2011), that alterations in motor unit recruitment might also modulate the $\dot{\mathrm{V}}_{\mathrm{O}_{2}}$ slow component during exercise above the GET [see Jones et al. (in press) for a recent review]. For example, an increase in $\dot{\mathrm{V}}_{\mathrm{O}_{2}}$ from the $3^{\text {rd }}$ to $6^{\text {th }}$ minute of constant work rate exercise has been shown to temporally coincide with markers of muscle activity (Endo, et al., 2007; Saunders, et al., 2000) and additional muscle fibre recruitment (Krustrup, Soderlund, Mohr, \& Bangsbo, 2004). It is therefore pertinent that an augmented $\mathrm{O}_{2}$ utilisation over the primary phase and subsequent reduction in the $\dot{\mathrm{V}}_{\mathrm{O} 2}$ slow component amplitude has been reported to coincide with reciprocal changes in the measured profile of the integrated electromyogram (iEMG) in quadriceps muscle (Bailey, Vanhatalo, Wilkerson, Dimenna, \& Jones, 2009; Burnley, Doust, Ball, \& Jones, 2002; c.f. Scheuermann, Hoelting, Noble, \& Barstow, 2001). However, to our knowledge, no previous study has quantified whether similar alterations in motor unit recruitment might contribute to the observed differences in the primary and slow component amplitudes between adults and children.

The primary purpose of this study was to utilise the work-to-work exercise model in combination with surface iEMG recordings in order to explore the influence of putative 
alterations in muscle fibre recruitment on $\dot{\mathrm{V}}_{\mathrm{O}_{2}}$ kinetics during exercise in boys aged 11$13 \mathrm{yr}$ and men. It was hypothesised that increasing the baseline work rate prior to very heavy-intensity transitions would lengthen the phase II $\dot{\mathrm{V}}_{\mathrm{O}_{2}} \tau$ and increase the total $\dot{\mathrm{V}}_{\mathrm{O}_{2}}$ gain in men, but would not alter the same $\dot{\mathrm{V}}_{\mathrm{O}_{2}}$ kinetic parameters in boys. We also hypothesised that unloaded-to-very heavy-intensity transitions would increase the primary $\dot{\mathrm{V}}_{\mathrm{O}_{2}}$ gain and reduce the relative $\dot{\mathrm{V}}_{\mathrm{O}_{2}}$ slow component in boys compared to men with a lower rate of change in iEMG activity over time in the former compared to latter age group.

\section{Methods}

\section{Participants}

Eight boys (mean \pm SD age $12.5 \pm 0.5 \mathrm{y}$, stature $1.49 \pm 0.06 \mathrm{~m}$, mass $38.9 \pm 4.1 \mathrm{~kg}$ ) and nine men (mean \pm SD age $26.0 \pm 2.9 \mathrm{y}$, stature $1.77 \pm 0.09 \mathrm{~m}$, mass $72.1 \pm 8.6 \mathrm{~kg}$ ) volunteered to participate in this study. Somatic maturity was estimated in the boys using sex-specific regression algorithms to determine a maturity offset score from age at peak height velocity (PHV) using anthropometric measurements (Mirwald, BaxterJones, Bailey, \& Beunen, 2002). These estimates yielded a mean offset score from PHV in the boys of $-2.3 \pm 0.5 \mathrm{yr}$ (range -1.6 to -2.9 ). Written, informed consent was obtained from each participant and the children's parent(s) / guardian(s) prior to the commencement of the study after verbal and written explanations of the study's aims, risks, and procedures were given. The procedures employed in this study were approved by the Institutional Research Ethics Committee. Participants were instructed to visit the laboratory in a rested and well hydrated state having also abstained from food or 
caffeine in the preceding $3 \mathrm{hr}$. In total, boys and men completed nine and five exercise tests respectively over a 4 wk period at approximately the same time of day ( $\pm 2 \mathrm{hr}$ ).

\section{Experimental procedures}

On the first visit, subjects performed a ramp incremental exercise test to voluntary exhaustion for determination of peak $\dot{\mathrm{V}}_{\mathrm{O}_{2}}$ and the gas exchange threshold (GET). After 3-min baseline cycling at $15 \mathrm{~W}$, the work rate increased continuously by $15 \mathrm{~W} \cdot \mathrm{min}^{-1}$ in boys and $30 \mathrm{~W} \cdot \mathrm{min}^{-1}$ in men to attain a test duration of approximately $8-12 \mathrm{~min}$ in each individual. Participants were instructed to select a preferred pedal rate of between $70-80$ $\mathrm{rev} \cdot \mathrm{min}^{-1}$ and maintain this cadence throughout the test. The peak $\dot{\mathrm{V}}_{\mathrm{O}_{2}}$ was taken as the highest recorded 10-s stationary average value during the incremental test which has been shown recently to reflect a maximum $\dot{\mathrm{V}}_{\mathrm{O}_{2}}$ in $93 \%$ of young people performing ramp exercise (Barker, Williams, Jones, \& Armstrong, 2009). The GET was determined non-invasively as the first disproportionate increase in $\mathrm{CO}_{2}$ production $\left(\dot{\mathrm{V}}_{\mathrm{CO}_{2}}\right)$ relative to the increase in $\dot{\mathrm{V}}_{\mathrm{O}_{2}}$ [i.e. the $\mathrm{V}$-slope method (1986)], and subsequently verified from visual inspection of the increase in the ventilatory equivalent for $\dot{\mathrm{V}}_{\mathrm{O}_{2}}\left(\dot{\mathrm{V}}_{\mathrm{E}} / \dot{\mathrm{V}}_{\mathrm{O}_{2}}\right)$ with no increase in $\dot{\mathrm{V}}_{\mathrm{E}} / \dot{\mathrm{V}}_{\mathrm{CO}_{2}}$.

The power outputs that would require $90 \%$ of the GET (moderate-intensity exercise) and $60 \%$ of the difference $(\Delta)$ between the GET and peak $\dot{\mathrm{V}}_{\mathrm{O}_{2}}$ (very heavy-intensity exercise, $\Delta 60 \%$ ) were estimated for each participant. Each participant then returned to the laboratory to perform one of two step exercise protocols: 1) 3-min of cycling at 15 $\mathrm{W}$, followed by 6-min of very heavy-intensity cycling $(\mathrm{U} \rightarrow \mathrm{VH})$; and 2) 3-min of 
cycling at $15 \mathrm{~W}$, followed by 4-min of moderate-intensity cycling $(\mathrm{U} \rightarrow \mathrm{M})$, followed by 6-min of very heavy-intensity cycling $(\mathrm{M} \rightarrow \mathrm{VH})$. A schematic illustration of the experimental protocol is shown in figure 1. Each child and adult completed four and two repetitions of protocols 1) and 2), respectively. Each protocol was presented to participants in random order with each laboratory visit separated by $\geq 48 \mathrm{hr}$.

All exercise tests were performed on an electronically-braked cycle ergometer (Lode Excalibur Sport, Groningen, the Netherlands) with the seat height, handlebar height, and crank length adapted to each subject and subsequently maintained throughout the testing period. Pulmonary gas exchange and ventilation were measured and displayed breathby-breath during each exercise trial (Metalyser 3B Cortex, Biophysik, Leipzig, Germany). Gas fractions of $\mathrm{O}_{2}$ and $\mathrm{CO}_{2}$ were drawn continuously from a face maskturbine assembly following calibration with gases of known concentration. Expired volume was measured using a DVT turbine digital transducer which was manually calibrated using a 3-L syringe (Hans Rudolph, Kansas City, MO) before each test. All calibration procedures were repeated before each experimental test. Heart rate (HR) was recorded every breath during all exercise tests using short-range radiotelemetry (Polar S610, Polar Electro Oy, Kempele, Finland).

Neuromuscular activity of the right leg $m$. vastus lateralis was measured using surface EMG. The right leg was initially abraded and cleaned to enhance the muscle electrical signal and graphite snap electrodes (Unilect 40713, Unomedical, Stonehouse, UK) were adhered to the skin surface in a bipolar arrangement (interelectrode distance: $40 \mathrm{~mm}$ ) positioned at the midway point between the greater trochanter and lateral epicondyle. A 
ground electrode was also placed on the m. rectus femoris bisecting the active electrodes with an elastic bandage wrapped around the participant's leg to prevent displacement of the electrodes during cycling. The EMG signal was recorded using a ME3000PB Muscle Tester (Mega Electronics).

EMG measurements at a sampling frequency of $1000 \mathrm{~Hz}$ were recorded throughout all exercise tests. The bipolar signal was amplified (amplifier input impedance $>1 \mathrm{M} \Omega$ ), and data were collected online in raw form and stored on a personal computer using MegaWin software (Mega Electronics). The raw EMG data were subsequently exported as an ASCII file and digitally filtered using Labview 8.2 (National Instruments, Newbury, UK). Initially, the signals were filtered with a $20-\mathrm{Hz}$ high-pass, second-order Butterworth filter to remove contamination from movement artefacts. The signal was then rectified and low-pass filtered at a frequency of $50 \mathrm{~Hz}$ to produce a linear envelope. The average iEMG was calculated for 15 -s time bins throughout exercise with these values normalized to the average measured during $15-180 \mathrm{~s}$ of cycling at $15 \mathrm{~W}$ before the initial step transition. Therefore, all iEMG data are presented as a percentage of the initial 'unloaded' cycling phase. Data from repeat trials were averaged, with the $\Delta \mathrm{iEMG}_{3-\mathrm{bl}}$ response defined as the difference between the average from $165-180 \mathrm{~s}$ and the average value recorded during baseline pedalling for each condition. We also used regression analysis in order to quantify the linear time vs. iEMG slope from the $\dot{\mathrm{V}}_{\mathrm{O}_{2}}$ slow component time delay to end-exercise $\left(\mathrm{iEMG}_{6-\mathrm{TD}_{2}}\right)$ during $\mathrm{U} \rightarrow \mathrm{VH}$ and $\mathrm{M} \rightarrow \mathrm{VH}$ exercise. 


\section{Data analysis procedures}

The breath-by-breath $\dot{\mathrm{V}}_{\mathrm{O}_{2}}$ data from each step exercise bout were initially examined to exclude errant breaths by removing values lying more than four standard deviations from the local mean determined using a 5-breath rolling average. Filtered $\dot{\mathrm{V}}_{\mathrm{O}_{2}}$ data were subsequently linearly interpolated to provide second-by-second values and, for each individual, identical repetitions of each exercise condition were time aligned to the start of exercise and averaged together to form a single data set for analysis.

The first $15 \mathrm{~s}$ of data after the onset of exercise were deleted to remove the phase I (cardio-dynamic) response, and the phase II portion of the $\dot{\mathrm{V}}_{2}$ response was modelled using the non-linear equation:

$$
\Delta \dot{\mathrm{V}}_{\mathrm{O}_{2}}(\mathrm{t})=\Delta \dot{\mathrm{V}}_{\mathrm{O}_{2}} \cdot\left(1-\mathrm{e}^{-(\mathrm{t}-\mathrm{TD}) / \tau}\right)
$$

where $\Delta \dot{\mathrm{V}}_{\mathrm{O}_{2}}(\mathrm{t}), \Delta \dot{\mathrm{V}}_{\mathrm{O}_{2}}$, TD and $\tau$ represent the value of $\dot{\mathrm{V}}_{\mathrm{O}_{2}}$ at a given time $(\mathrm{t})$, the amplitude change in $\dot{\mathrm{V}}_{2}$ from baseline to its asymptote, time delay and the time constant of the response, respectively. In order to identify an optimal fitting window with which to estimate parameters of the phase II response, a purpose-designed software program developed with LabVIEW (National Instruments, Newbury, UK) was used. The fitting window was iteratively widened by $1 \mathrm{~s}$ intervals, starting from a $60 \mathrm{~s}$ fitting window and finishing with a fitting window that encompassed the entire data set (Rossiter, et al., 2001). The estimated $\tau$ for each fitting window was plotted against time to allow the beginning of the $\dot{\mathrm{V}}_{\mathrm{O}_{2}}$ slow component to be determined through visual 
inspection. The onset of the $\dot{\mathrm{V}}_{\mathrm{O}_{2}}$ slow component was defined as the point at which a plateau in the estimated $\tau$ was followed by a progressive increase in the estimated $\tau$. The phase II parameter estimates from Eq. 1 were then resolved by least-squares non-linear regression (GraphPad Prism, GraphPad Software, San Diego, CA). The amplitude of the $\dot{\mathrm{V}}_{\mathrm{O}_{2}}$ slow component was calculated as the difference between the mean of the last $30 \mathrm{~s}$ of exercise and the phase II asymptote and expressed in relative terms against the $\dot{\mathrm{V}}_{\mathrm{o}_{2}}$ at end exercise. To provide information on the 'overall' $\dot{\mathrm{V}}_{\mathrm{O}_{2}}$ kinetics [mean response time (MRT)], Eq. 1 with TD constrained to $0 \mathrm{~s}$ (i.e. no delay term) was fit from the onset to the end of exercise. For all conditions the functional gain of the primary $\dot{\mathrm{V}}_{\mathrm{O}_{2}}$ response was calculated by dividing the asymptotic primary phase amplitude by the increment in work rate above baseline $\left(\Delta \dot{\mathrm{V}}_{\mathrm{O}_{2}} / \Delta \mathrm{WR}\right)$. Likewise, the end-exercise $\dot{\mathrm{V}}_{\mathrm{O}_{2}}$ gain was calculated using a similar technique.

HR kinetics was also modelled for each condition within a fitting window that excluded any slow phase in the HR response with the $T D$ parameter in Eq. 1 . constrained to $t=0$ s (i.e. monoexponential model with no delay).

\section{Statistical Analysis}

Mean differences in $\dot{\mathrm{V}}_{\mathrm{O}_{2}}$, iEMG, and HR parameters were examined using a two-way repeated-measures ANOVA with Bonferroni adjusted post hoc tests used in order to locate statistically significant differences between and within groups. Pearson productmoment correlation coefficients were used to investigate relationships between the 
parameters of $\dot{\mathrm{V}}_{\mathrm{O}_{2}}, \mathrm{HR}$, and iEMG. All results are presented as means $\pm \mathrm{SD}$ with rejection of the null hypotheses accepted at an alpha level of 0.05 .

\section{Results}

The subjects' peak $\dot{\mathrm{V}}_{\mathrm{O}_{2}}$ was $1.94 \pm 0.14 \mathrm{~L} \cdot \mathrm{min}^{-1}$ and $3.25 \pm 0.62 \mathrm{~L} \cdot \mathrm{min}^{-1}$ in boys and men respectively, with the GET occurring at a similar fraction of peak $\dot{\mathrm{V}}_{\mathrm{O}_{2}}$ in both groups (Boys: $50 \pm 3$ vs. Men: $45 \pm 8 \%$ ). Based on the ramp exercise responses, the work rates calculated to require $90 \%$ of the GET and $\Delta 60 \%$ were $42 \pm 4$ and $115 \pm 7 \mathrm{~W}$ in boys and $101 \pm 19$ and $230 \pm 28 \mathrm{~W}$ in men.

\section{$\dot{\mathrm{V}}_{\mathrm{O}_{2}}$ kinetics}

Table 1 presents the participants' $\dot{\mathrm{V}}_{\mathrm{O}_{2}}$ kinetic responses for each condition. An example $\dot{\mathrm{V}}_{\mathrm{O}_{2}}$ response for a typical child and adult participant in each exercise condition is shown in figure 2. Group mean $\dot{\mathrm{V}}_{\mathrm{O}_{2}}$ responses at the onset of $\mathrm{U} \rightarrow \mathrm{VH}$ and $\mathrm{M} \rightarrow \mathrm{VH}$ exercise in boys are presented in figure 3. Step exercise was initiated from an elevated baseline $\dot{\mathrm{V}}_{\mathrm{O}_{2}}$ in $\mathrm{M} \rightarrow \mathrm{VH}$ compared to $\mathrm{U} \rightarrow \mathrm{M}$ and $\mathrm{U} \rightarrow \mathrm{VH}$ exercise in both groups ( $\mathrm{p}<0.001)$. The phase II $\dot{\mathrm{V}}_{\mathrm{O}_{2}} \tau$ was slower in $\mathrm{M} \rightarrow \mathrm{VH}$ compared to the other exercise conditions in both boys and men $(\mathrm{p}<0.028)$. However, phase II $\dot{\mathrm{V}}_{\mathrm{O}_{2}}$ kinetics were not different between $\mathrm{U} \rightarrow \mathrm{M}$ and $\mathrm{U} \rightarrow \mathrm{VH}$ exercise in boys $(\mathrm{p}=0.26)$ or men $(\mathrm{p}=$ 0.64). Boys had a faster phase II $\tau$ compared to men in each exercise condition ( $\mathrm{p}<$ $0.007)$. 
The primary $\dot{\mathrm{V}}_{\mathrm{O}_{2}}$ gain was reduced in $\mathrm{U} \rightarrow \mathrm{VH}$ and $\mathrm{M} \rightarrow \mathrm{VH}$ compared to $\mathrm{U} \rightarrow \mathrm{M}$ in boys $(\mathrm{p}<0.04)$ but there were no significant differences for this parameter across exercise conditions in men $(\mathrm{p}>0.114)$. During $\mathrm{U} \rightarrow \mathrm{VH}$ exercise, there were no significant group differences in the primary $\dot{\mathrm{V}}_{\mathrm{O}_{2}}$ gain $(\mathrm{p}=0.10)$, however, the relative $\dot{\mathrm{V}}_{\mathrm{O}_{2}}$ slow component was increased in men compared to boys $(\mathrm{p}=0.022)$. The absolute $\dot{\mathrm{V}}_{\mathrm{O}_{2}}$ slow component amplitude was also reduced in $\mathrm{M} \rightarrow \mathrm{VH}$ compared to $\mathrm{U} \rightarrow \mathrm{VH}$ within men ( $\mathrm{p}$ $=0.033)$. The total $\dot{\mathrm{V}}_{\mathrm{O}_{2}}$ gain increased from $\mathrm{U} \rightarrow \mathrm{M}$ to $\mathrm{U} \rightarrow \mathrm{VH}$ in men $(\mathrm{p}=0.006)$ with this value further extended in $\mathrm{M} \rightarrow \mathrm{VH}$ compared to other exercise conditions in adult subjects $(\mathrm{p}=0.003)$. By contrast, there were no differences in the total $\dot{\mathrm{V}}_{\mathrm{O} 2}$ gain between conditions in boys $(\mathrm{p}>0.99)$.

\section{HR kinetics}

Table 2 presents the mean HR responses to exercise in each condition. Group mean HR responses following the onset of $\mathrm{U} \rightarrow \mathrm{VH}$ and $\mathrm{M} \rightarrow \mathrm{VH}$ in boys are presented in figure 3 . Baseline HR was increased prior to the onset of $\mathrm{M} \rightarrow \mathrm{VH}$ exercise in boys and men compared to the other conditions $(\mathrm{p}<0.001)$. The HR $\tau$ was not significantly different between $\mathrm{U} \rightarrow \mathrm{VH}$ and $\mathrm{M} \rightarrow \mathrm{VH}$ exercise in either boys $(\mathrm{p}=0.51)$ or men $(\mathrm{p}=0.63)$. Relative (\%) changes in the phase II $\dot{\mathrm{V}}_{\mathrm{O}_{2}} \tau$ between $\mathrm{U} \rightarrow \mathrm{VH}$ and $\mathrm{M} \rightarrow \mathrm{VH}$ were not significantly correlated with alterations in HR kinetics in boys $(r=0.55, p=0.16)$ or men $(r=-0.56, p=0.19)$. 
Group mean iEMG responses following the onset of step exercise are presented in figure 4 for each condition. Baseline pedalling during $\mathrm{M} \rightarrow \mathrm{VH}$ significantly increased iEMG activity in both groups (Boys: $192 \pm 69$ vs. Men: $237 \pm 64 \%$ ) compared to other exercise conditions $(\mathrm{p}<0.022)$ with a reduced $\Delta \mathrm{iEMG}_{3-\mathrm{bl}}$ response in $\mathrm{M} \rightarrow \mathrm{VH}$ relative to $\mathrm{U} \rightarrow \mathrm{VH}$ in boys $(205 \pm 87$ vs. $316 \pm 105 \%, \mathrm{p}=0.021)$ and $\operatorname{men}(206 \pm 79$ vs. $335 \pm$ $148 \%, \mathrm{p}=0.006)$. Figure 5 presents $\mathrm{iEMG}$ responses during $\mathrm{U} \rightarrow \mathrm{VH}$ exercise in a representative child and adult subject. Two-way ANOVA revealed a significant age $\times$ time interaction effect for iEMG activity during $\mathrm{U} \rightarrow \mathrm{VH}$ exercise $(\mathrm{p}=0.002)$. In men, follow-up post hoc tests located significant increases in iEMG from $60 \mathrm{~s}$ to $180 \mathrm{~s}(406 \pm$ 145 vs. $434 \pm 148 \%, p=0.018)$ and from 180 s to $360 \mathrm{~s}(434 \pm 148$ vs. $468 \pm 146 \%, p=$ 0.027 ) but there were no differences in iEMG across time points within boys ( $p>0.21)$. Linear regression revealed a significantly greater $\mathrm{iEMG}_{6-\mathrm{TD}} 2$ slope during $\mathrm{U} \rightarrow \mathrm{VH}$ in men compared to boys $(0.19 \pm 0.24$ vs. $-0.06 \pm 0.14 \%, \mathrm{p}=0.022)$ but there were no group differences for this parameter in $\mathrm{M} \rightarrow \mathrm{VH}(0.11 \pm 0.19$ vs. $0.08 \pm 0.12 \%, \mathrm{p}=$

0.63). The relative $\dot{\mathrm{V}}_{\mathrm{O}_{2}}$ slow component amplitude was not correlated to the $\mathrm{iEMG}_{6-\mathrm{TD}}{ }_{2}$ slope during $\mathrm{U} \rightarrow \mathrm{VH}$ and $\mathrm{M} \rightarrow \mathrm{VH}$ in either boys $(\mathrm{r}=0.08$ vs. $-0.39, \mathrm{p}>$ $0.34)$ or men ( $r=0.11$ vs. $0.63, \mathrm{p}>0.07)$.

\section{Discussion}

The principle original finding of this investigation was that step transitions to very heavy-intensity exercise initiated from an elevated baseline work rate resulted in altered phase II $\dot{\mathrm{V}}_{\mathrm{O}_{2}}$ kinetics independent of age compared to transitions elicited from unloaded pedaling. Contrary to our hypothesis, 'work-to-work' transitions extended the phase II $\tau$ in boys and men, however, increases in the total $\dot{\mathrm{V}}_{\mathrm{O}_{2}}$ gain were confined to 
adult subjects in this condition compared to U-M and U-VH exercise. Furthermore, a lower relative $\dot{\mathrm{V}}_{\mathrm{O}_{2}}$ slow component amplitude during constant work rate exercise above the GET coincided with a reduced rate of change in iEMG over time in boys compared to men. These findings provide novel insight into the physiological factors linked to an age dependent modulation of $\dot{\mathrm{V}}_{\mathrm{O}_{2}}$ kinetics during intense submaximal exercise.

The Fick principle dictates that pulmonary $\dot{\mathrm{V}}_{\mathrm{O}_{2}}$ (and by extension $\mathrm{m} \dot{\mathrm{V}}_{\mathrm{O}_{2}}$ ) kinetics is influenced by the rate of muscle $\mathrm{O}_{2}$ delivery and peripheral factors linked to $\mathrm{O}_{2}$ utilisation during step transitions from a lower to higher metabolic rate. In the case of the former, it has been suggested that an elevated pre-transition work rate (and thus HR) might slow the adjustment in cardiac output ( $\dot{\mathrm{Q}}$ ) and hence accentuate an $\mathrm{O}_{2}$ supply limitation to $\dot{\mathrm{V}}_{\mathrm{O}_{2}}$ kinetics under these circumstances (Hughson \& Morrissey, 1982; MacPhee, et al., 2005). It is therefore pertinent that a lengthened phase II $\tau$ from $\mathrm{U} \rightarrow \mathrm{VH}$ to $\mathrm{M} \rightarrow \mathrm{VH}$ was not associated with any concomitant alterations in HR kinetics with no significant differences reported in the primary HR $\tau$ between these two conditions in boys. Assuming a minimal contribution from alterations in stroke volume on changes in $\dot{\mathrm{Q}}$ from the onset of $\mathrm{M} \rightarrow \mathrm{VH}$ exercise (Bearden \& Moffatt, 2001), the present results suggest that phase II $\dot{\mathrm{V}}_{\mathrm{O}_{2}}$ kinetics were unlikely restricted by a slower adaptation in cardiac output $(\dot{\mathrm{Q}})$ and hence bulk $\mathrm{O}_{2}$ delivery across the work-to-work transient in children. These findings are consistent with previous studies in adults (DiMenna, et al., 2008; Wilkerson \& Jones, 2006) and therefore lend further support to the notion that intracellular factors principally limit $\dot{\mathrm{V}}_{\mathrm{O}_{2}}$ kinetics at the onset of upright 
cycling above the GET in youth (Barker, Jones, \& Armstrong, 2010). However, the extent to which spatial differences in matching $\mathrm{O}_{2}$ supply to the rate of $\mathrm{O}_{2}$ utilisation ( $\dot{\mathrm{Q}}_{\mathrm{O}_{2}} / \dot{\mathrm{V}}_{\mathrm{O}_{2}}$ ) influenced $\dot{\mathrm{V}}_{\mathrm{O}_{2}}$ kinetics during work-to-work exercise is unclear from the present study.

Recent demonstrations that the $\tau$ for phase II $\dot{\mathrm{V}}_{\mathrm{O}_{2}}$ and primary $[\mathrm{PCr}]$ kinetics were not speeded during work-to-work transitions following prior exercise has been interpreted to suggest that muscle fibres with a limited capacity to utilise $\mathrm{O}_{2}$ may be predominantly recruited at the onset of exercise in this condition (Dimenna, Fulford, et al., 2010; DiMenna, et al., 2008). This supposition is based on an orderly recruitment of motor units in relation to size and the intensity of muscle contractile activity (Henneman \& Mendell, 1981). For example, smaller motoneurones that innervate fewer muscle fibres with a greater mitochondrial volume and/or oxidative enzyme activity (i.e. type I motor units) are recruited initially at low force outputs (i.e. during the $U \rightarrow M$ condition in the present study). Conversely, depolarisation of the higher-order (type II) motor units requires an increased level of excitatory input, for example, as the requirement for muscle force production is increased (i.e. during VH exercise). From the present study, this might predict that $\mathrm{U} \rightarrow \mathrm{VH}$ transitions recruited a heterogeneous population of muscle fibres (with varying individual $\tau$ values) following the onset of exercise in boys and men. Conversely, initiating step exercise from an elevated work rate might have reduced the total number of muscles fibres recruited in this condition to those positioned higher in the recruitment hierarchy (i.e. consistent with a reduced $\Delta \mathrm{iEMG}_{3 \text {-bl }}$ response in $\mathrm{M} \rightarrow \mathrm{VH}$ compared to $\mathrm{U} \rightarrow \mathrm{VH}$ ). Higher-order (type II) fibres are reported to have a reduced microvascular $\mathrm{O}_{2}$ pressure head, slower $\dot{\mathrm{V}}_{\mathrm{O}_{2}}$ kinetics, and an increased $\mathrm{O}_{2}$ per 
unit of tension development compared to type I fibres (Behnke, McDonough, Padilla, Musch, \& Poole, 2003; Crow \& Kushmerick, 1982; Krustrup, et al., 2008; McDonough, Behnke, Padilla, Musch, \& Poole, 2005). However, due to ethical restrictions, we were unable to establish the extent to which differences in muscle fibre recruitment directly impacted on $\dot{\mathrm{V}}_{\mathrm{O}_{2}}$ kinetics between exercise conditions.

Consistent with previous studies (Breese, et al., 2010; Fawkner \& Armstrong, 2004; Williams, et al., 2001), $\mathrm{U} \rightarrow \mathrm{VH}$ transitions yielded faster phase II $\dot{\mathrm{V}}_{\mathrm{O}_{2}}$ kinetics in younger compared to older counterparts. Although the mechanisms are unknown, the previous demonstration of a negative correlation between the percentage of type I muscle fibres and the phase II $\tau$ in adults (Pringle, et al., 2003) has been interpreted to suggest that differences in muscle fibre recruitment might be linked to age differences following the onset of heavy/very heavy exercise (Armstrong \& Barker, 2009). We therefore utilised the work-to-work model in order to explore the proposal than children's phase II $\dot{\mathrm{V}}_{2}$ kinetics might be less amenable to alterations in muscle fibre recruitment when contractile activity is increased prior to the initiation of step exercise. This did not manifest, since step transitions from $\mathrm{U} \rightarrow \mathrm{M}$ to $\mathrm{M} \rightarrow \mathrm{VH}$ yielded a comparable relative slowing of the phase II $\tau$ between boys and men (58\% vs. $63 \%$, respectively). However, it is interesting to note that dividing a full $\mathrm{U} \rightarrow \mathrm{VH}$ transition into two discrete step bouts (i.e. $\mathrm{U} \rightarrow \mathrm{M}$ and $\mathrm{M} \rightarrow \mathrm{VH}$ ) yielded faster phase II $\dot{\mathrm{V}}_{\mathrm{O} 2}$ kinetics in boys compared to men in each step. This might predict a longer $\tau$ in men relative to boys if similar muscle fibre pools recruited in $\mathrm{U} \rightarrow \mathrm{M}$ and $\mathrm{M} \rightarrow \mathrm{VH}$ were to contribute to the external power output (and hence influence the rise in $\dot{\mathrm{V}}_{\mathrm{O}_{2}}$ ) from the onset of $\mathrm{U} \rightarrow \mathrm{VH}$ exercise. Whilst muscle fibre recruitment cannot be established from 
the present study, the demonstration that glycogen content is reduced in single type I and II muscle fibres following the onset of intense $\left(80 \%\right.$ peak $\left.\dot{\mathrm{V}}_{\mathrm{O}_{2}}\right)$ cycling exercise in adults (Krustrup, et al., 2004) is, at least in part, consistent with this proposal.

An implicit assumption based on the aforementioned muscle fibre recruitment profile is that the phase II $\tau$ would be lengthened during exercise above compared to below the GET if the metabolic properties of the higher-order (type II) muscle fibres were involved in modulating the $\dot{\mathrm{V}}_{\mathrm{O}_{2}}$ response earlier into the transition. Contrary to this notion, similar phase II $\dot{\mathrm{V}}_{\mathrm{O}_{2}}$ kinetics between $\mathrm{U} \rightarrow \mathrm{M}$ and $\mathrm{U} \rightarrow \mathrm{VH}$ exercise in boys $(\tau=$ $19 \mathrm{~s}$ vs. $21 \mathrm{~s}$ ) suggests that the phase II $\tau$ is independent of exercise intensity (at least for work rates spanning the moderate-to-very heavy-intensity domains) in young people (Lai, et al., 2008; Williams, et al., 2001). We reported similar results in men, although it is conceivable that large inter-subject variability in the parameter estimates combined with small sample sizes might have reduced the statistical power necessary to detect meaningful differences (Poole \& Jones, 2005). However, assuming that transitions from unloaded pedalling to $\Delta 60 \%$ recruited a large proportion of the total muscle fibre pool in our subjects (Sargeant, 1999), it is possible to reconcile $\dot{\mathrm{V}}_{\mathrm{O}_{2}}$ responses in the $\mathrm{M} \rightarrow \mathrm{VH}$ condition with a lower relative $\dot{\mathrm{V}}_{\mathrm{O}_{2}}$ slow component amplitude during $\mathrm{U} \rightarrow \mathrm{VH}$ exercise in boys compared to men. For example, it has been suggested that the protracted response of earlier recruited muscle fibres with slower $\dot{\mathrm{V}}_{\mathrm{O}_{2}}$ kinetics might be involved in creating a $\dot{\mathrm{V}}_{\mathrm{O}_{2}}$ slow component of delayed onset (Wilkerson \& Jones, 2007). It is therefore pertinent that $\mathrm{M} \rightarrow \mathrm{VH}$ increased the total $\dot{\mathrm{V}}_{\mathrm{O}_{2}}$ gain (39\%) relative to $\mathrm{U} \rightarrow \mathrm{M}$ in men, but there were no differences between conditions for this parameter in 
boys. This might predict that higher-order muscle fibres if recruited following the onset of $\mathrm{U} \rightarrow \mathrm{VH}$ exercise could have extended the rise in $\dot{\mathrm{V}}_{\mathrm{O}_{2}}$ above the phase II asymptote in men compared to boys. (Note, however, in accord with this model that faster $\dot{\mathrm{V}}_{\mathrm{O}_{2}}$ kinetics in earlier recruited fibres would predict a shorter $\dot{\mathrm{V}}_{\mathrm{O}_{2}}$ slow component TD in boys compared to men which was not present in $\mathrm{U} \rightarrow \mathrm{VH}$ )

Alternatively, acceptance that the $\dot{\mathrm{V}}_{\mathrm{O}_{2}}$ slow component is elicited after an independent time delay (Barstow \& Mole, 1991) is consistent with the notion that the delayed activation of muscle fibres might be principally linked to increasing the $\mathrm{O}_{2}$ cost of the external power output as exercise proceeds (Endo, et al., 2007; Krustrup, et al., 2004; Whipp, 1994). Therefore, a novel finding from the present investigation was that a lower relative $\dot{\mathrm{V}}_{\mathrm{O}_{2}}$ slow component amplitude coincided with a reduced rate of change in iEMG of the $m$. vastus lateralis in boys compared to men during $\mathrm{U} \rightarrow \mathrm{VH}$ exercise. These results might be interpreted to suggest that a lower rate of fatigue development in youth subjects negated the requirement for either increased motor unit firing frequency and/or recruitment of previously inactive muscle fibres in order to sustain constant work rate exercise. However, the possibility that interrogation of superficial electrical activity rendered the iEMG signal insensitive to locating spatial differences in muscle activation patterns between boys and men cannot be discounted. Furthermore, it is also important to consider that increases in iEMG from $60 \mathrm{~s}$ to $180 \mathrm{~s}$ preceded the onset of a slow rise in $\dot{\mathrm{V}}_{\mathrm{O}_{2}}$ during $\mathrm{U} \rightarrow \mathrm{VH}$ exercise $\left(\mathrm{TD}_{2}=155 \mathrm{~s}\right)$ in men with no correlation reported between the $\mathrm{iEMG}_{6-\mathrm{TD} 2}$ slope and the relative $\dot{\mathrm{V}}_{\mathrm{O}_{2}}$ slow component amplitude in either age group. Previous reports that markers of muscle activity are associated both 
temporally and in magnitude with the $\dot{\mathrm{V}}_{\mathrm{O}_{2}}$ slow component (Borrani, et al., 2001; Endo, et al., 2007; Saunders, et al., 2000; Shinohara \& Moritani, 1992) were therefore not corroborated by the present study.

\section{Conclusion}

This study combined work-to-work exercise transitions with measurements of the integrated electromyogram (iEMG) in order to explore the putative factors involved in modulating $\dot{\mathrm{V}}_{\mathrm{O}_{2}}$ kinetics in relation to age. Step transitions to very heavy exercise initiated from an elevated baseline work rate lengthened the phase II $\tau$ in men compared to boys and extended the overall $\dot{\mathrm{V}}_{\mathrm{O} 2}$ gain within adults only compared to transitions elicited from unloaded pedalling. Furthermore, an elevated $\dot{\mathrm{V}}_{\mathrm{O}_{2}}$ slow component during unloaded-to-very heavy exercise was accompanied by an increased surface iEMG activity of the m. vastus lateralis in men compared to boys. These findings are consistent with the notion that age related differences in $\dot{\mathrm{V}}_{\mathrm{O}_{2}}$ kinetics are linked to alterations in muscle fibre recruitment following the onset of very heavy-intensity exercise. 
Armon, Y., Cooper, D. M., Flores, R., Zanconato, S., \& Barstow, T. J. (1991). Oxygen uptake dynamics during high-intensity exercise in children and adults. J Appl Physiol, 70(2), 841-848.

Armstrong, N., \& Barker, A. R. (2009). Oxygen uptake kinetics in children and adolescents: a review. Pediatr Exerc Sci, 21(2), 130-147.

Bailey, S. J., Vanhatalo, A., Wilkerson, D. P., Dimenna, F. J., \& Jones, A. M. (2009). Optimizing the "priming" effect: influence of prior exercise intensity and recovery duration on $\mathrm{O} 2$ uptake kinetics and severe-intensity exercise tolerance. J Appl Physiol, 107(6), 17431756.

Barker, A. R., Jones, A. M., \& Armstrong, N. (2010). The influence of priming exercise on oxygen uptake, cardiac output, and muscle oxygenation kinetics during very heavyintensity exercise in 9- to 13-yr-old boys. J Appl Physiol, 109(2), 491-500.

Barker, A. R., Williams, C. A., Jones, A. M., \& Armstrong, N. (2009). Establishing maximal oxygen uptake in young people during a ramp cycle test to exhaustion. Br J Sports Med, 45(6), 498-503.

Barstow, T. J., \& Mole, P. A. (1991). Linear and nonlinear characteristics of oxygen uptake kinetics during heavy exercise. J Appl Physiol, 71(6), 2099-2106.

Bearden, S. E., \& Moffatt, R. J. (2001). VO2 and heart rate kinetics in cycling: transitions from an elevated baseline. J Appl Physiol, 90(6), 2081-2087.

Beaver, W. L., Wasserman, K., \& Whipp, B. J. (1986). A new method for detecting anaerobic threshold by gas exchange. J Appl Physiol, 60(6), 2020-2027.

Behnke, B. J., McDonough, P., Padilla, D. J., Musch, T. I., \& Poole, D. C. (2003). Oxygen exchange profile in rat muscles of contrasting fibre types. J Physiol, 549(Pt 2), 597-605.

Borrani, F., Candau, R., Millet, G. Y., Perrey, S., Fuchslocher, J., \& Rouillon, J. D. (2001). Is the VO2 slow component dependent on progressive recruitment of fast-twitch fibers in trained runners? J Appl Physiol, 90(6), 2212-2220.

Breese, B. C., Armstrong, N., Barker, A. R., \& Williams, C. A. (2011). The effect of pedal rate on pulmonary $\mathrm{O}(2)$ uptake kinetics during very heavy intensity exercise in trained and untrained teenage boys. Respir Physiol Neurobiol, 177(2), 149-154.

Breese, B. C., Williams, C. A., Barker, A. R., Welsman, J. R., Fawkner, S. G., \& Armstrong, N. (2010). Longitudinal changes in the oxygen uptake kinetic response to heavy-intensity exercise in 14- to 16-year-old boys. Pediatr Exerc Sci, 22(1), 69-80.

Brittain, C. J., Rossiter, H. B., Kowalchuk, J. M., \& Whipp, B. J. (2001). Effect of prior metabolic rate on the kinetics of oxygen uptake during moderate-intensity exercise. Eur J Appl Physiol, 86(2), 125-134.

Burnley, M., Doust, J. H., Ball, D., \& Jones, A. M. (2002). Effects of prior heavy exercise on $\mathrm{VO}(2)$ kinetics during heavy exercise are related to changes in muscle activity. J Appl Physiol, 93(1), 167-174.

c.f. Scheuermann, B. W., Hoelting, B. D., Noble, M. L., \& Barstow, T. J. (2001). The slow component of $\mathrm{O}(2)$ uptake is not accompanied by changes in muscle EMG during repeated bouts of heavy exercise in humans. J Physiol, 531(Pt 1), 245-256.

Crow, M. T., \& Kushmerick, M. J. (1982). Chemical energetics of slow- and fast-twitch muscles of the mouse. J Gen Physiol, 79(1), 147-166. 
Dimenna, F. J., Bailey, S. J., Vanhatalo, A., Chidnok, W., \& Jones, A. M. (2010). Elevated baseline VO2 per se does not slow 02 uptake kinetics during work-to-work exercise transitions. J Appl Physiol, 109(4), 1148-1154.

Dimenna, F. J., Fulford, J., Bailey, S. J., Vanhatalo, A., Wilkerson, D. P., \& Jones, A. M. (2010). Influence of priming exercise on muscle $[\mathrm{PCr}]$ and pulmonary $\mathrm{O} 2$ uptake dynamics during 'work-to-work' knee-extension exercise. Respir Physiol Neurobiol, 172(1-2), 1523.

DiMenna, F. J., Wilkerson, D. P., Burnley, M., \& Jones, A. M. (2008). Influence of priming exercise on pulmonary $\mathrm{O} 2$ uptake kinetics during transitions to high-intensity exercise from an elevated baseline. J Appl Physiol, 105(2), 538-546.

Endo, M. Y., Kobayakawa, M., Kinugasa, R., Kuno, S., Akima, H., Rossiter, H. B., et al. (2007). Thigh muscle activation distribution and pulmonary $\mathrm{VO} 2$ kinetics during moderate, heavy, and very heavy intensity cycling exercise in humans. Am J Physiol Regul Integr Comp Physiol, 293(2), R812-820.

Fawkner, S. G., \& Armstrong, N. (2004). Longitudinal changes in the kinetic response to heavyintensity exercise in children. J Appl Physiol, 97(2), 460-466.

Henneman, E., \& Mendell, L. M. (1981). Functional Organisation of a Motorneuron Pool and its Inputs. In V. B. Brooks (Ed.), Handbook of Physiology I, Vol. II, Part 1 (pp. 423-507): American Physiological Society, Bethesda.

Hughson, R. L., \& Morrissey, M. (1982). Delayed kinetics of respiratory gas exchange in the transition from prior exercise. J Appl Physiol, 52(4), 921-929.

Jones, A. M., Grassi, B., Christensen, P. M., Krustrup, P., Bangsbo, J., \& Poole, D. C. (in press). The Slow Component of V O2 Kinetics: Mechanistic Bases and Practical Applications. Med Sci Sports Exerc.

Krustrup, P., Jones, A. M., Wilkerson, D. P., Calbet, J. A., \& Bangsbo, J. (2009). Muscular and pulmonary $\mathrm{O} 2$ uptake kinetics during moderate- and high-intensity sub-maximal kneeextensor exercise in humans. J Physiol, 587(Pt 8), 1843-1856.

Krustrup, P., Secher, N. H., Relu, M. U., Hellsten, Y., Soderlund, K., \& Bangsbo, J. (2008). Neuromuscular blockade of slow twitch muscle fibres elevates muscle oxygen uptake and energy turnover during submaximal exercise in humans. J Physiol, 586(Pt 24), 6037-6048.

Krustrup, P., Soderlund, K., Mohr, M., \& Bangsbo, J. (2004). The slow component of oxygen uptake during intense, sub-maximal exercise in man is associated with additional fibre recruitment. Pflugers Arch, 447(6), 855-866.

Lai, N., Nasca, M. M., Silva, M. A., Silva, F. T., Whipp, B. J., \& Cabrera, M. E. (2008). Influence of exercise intensity on pulmonary oxygen uptake kinetics at the onset of exercise and recovery in male adolescents. Appl Physiol Nutr Metab, 33(1), 107-117.

MacPhee, S. L., Shoemaker, J. K., Paterson, D. H., \& Kowalchuk, J. M. (2005). Kinetics of O2 uptake, leg blood flow, and muscle deoxygenation are slowed in the upper compared with lower region of the moderate-intensity exercise domain. J Appl Physiol, 99(5), 1822-1834.

McDonough, P., Behnke, B. J., Padilla, D. J., Musch, T. I., \& Poole, D. C. (2005). Control of microvascular oxygen pressures in rat muscles comprised of different fibre types. $J$ Physiol, 563(Pt 3), 903-913.

Mirwald, R. L., Baxter-Jones, A. D., Bailey, D. A., \& Beunen, G. P. (2002). An assessment of maturity from anthropometric measurements. Med Sci Sports Exerc, 34(4), 689-694.

Poole, D. C., \& Jones, A. M. (2005). Towards an understanding of the mechanistic bases of VO2 kinetics. In A. M. Jones \& D. C. Poole (Eds.), Oxygen Uptake Kinetics in Sport, Exercise and Medicine. (pp. 294-328). London and New York: Routledge 
Pringle, J. S., Doust, J. H., Carter, H., Tolfrey, K., Campbell, I. T., Sakkas, G. K., et al. (2003). Oxygen uptake kinetics during moderate, heavy and severe intensity "submaximal" exercise in humans: the influence of muscle fibre type and capillarisation. Eur J Appl Physiol, 89(3-4), 289-300.

Rossiter, H. B., Ward, S. A., Kowalchuk, J. M., Howe, F. A., Griffiths, J. R., \& Whipp, B. J. (2001). Effects of prior exercise on oxygen uptake and phosphocreatine kinetics during highintensity knee-extension exercise in humans. J Physiol, 537(Pt 1), 291-303.

Sargeant, A. J. (1999). Neuromuscular determinants of human performance. In B. J. Whipp \& A. J. Sargeant (Eds.), Physiological Determinants of Exercise Tolerance in Humans. (pp. 1328). London: Portland Press.

Saunders, M. J., Evans, E. M., Arngrimsson, S. A., Allison, J. D., Warren, G. L., \& Cureton, K. J. (2000). Muscle activation and the slow component rise in oxygen uptake during cycling. Med Sci Sports Exerc, 32(12), 2040-2045.

Shinohara, M., \& Moritani, T. (1992). Increase in neuromuscular activity and oxygen uptake during heavy exercise. Ann Physiol Anthropol, 11(3), 257-262.

Whipp, B. J. (1994). The slow component of O2 uptake kinetics during heavy exercise. Med Sci Sports Exerc, 26(11), 1319-1326.

Wilkerson, D. P., \& Jones, A. M. (2006). Influence of initial metabolic rate on pulmonary 02 uptake on-kinetics during severe intensity exercise. Respir Physiol Neurobiol, 152(2), 204-219.

Wilkerson, D. P., \& Jones, A. M. (2007). Effects of baseline metabolic rate on pulmonary $\mathrm{O} 2$ uptake on-kinetics during heavy-intensity exercise in humans. Respir Physiol Neurobiol, 156(2), 203-211.

Williams, C. A., Carter, H., Jones, A. M., \& Doust, J. H. (2001). Oxygen uptake kinetics during treadmill running in boys and men. J Appl Physiol, 90(5), 1700-1706. 


\section{Figure Legends}

Fig. 1. Schematic illustration of the experimental protocol including each exercise condition.

Fig. 2. $\dot{\mathrm{V}}_{\mathrm{O} 2}$ kinetic responses to moderate- and very heavy-intensity exercise in a representative child $(\bullet)$ and adult $(\circ)$ subject. Solid grey lines denote the phase II model fit in each condition. The onset of step exercise is indicated by the vertical dotted line.

Fig. 3. Mean $\dot{\mathrm{V}}_{\mathrm{O}_{2}}$ and HR responses (upper and lower panels, respectively) following the onset of $\mathrm{U} \rightarrow \mathrm{VH}(\bullet)$ and $\mathrm{M} \rightarrow \mathrm{VH}(\circ)$ exercise in boys. The data are normalised to the end-exercise amplitude minus the averaged value measured during baseline exercise.

Fig. 4. Mean \pm S.E. integrated electromyogram (iEMG) response following the onset of step exercise in boys (closed bars) and men (open bars). The data are normalised to the averaged 'unloaded' value and are presented as the difference $(\Delta)$ above baseline pedalling to the $3^{\text {rd }}$ min of exercise in each condition. * Significantly different from $\mathrm{U} \rightarrow \mathrm{M}$ condition. \#Significantly different from $\mathrm{U} \rightarrow \mathrm{VH}$ condition (both $\mathrm{p}<0.05$ ).

Fig. 5. Muscle iEMG response in a representative child $(\bullet)$ and adult $(\circ)$ subject during $\mathrm{U} \rightarrow \mathrm{VH}$ exercise. The data are fitted using a linear function from the $\dot{\mathrm{V}}_{\mathrm{O}_{2}}$ slow component time delay to the end of exercise in each subject. 
Table $1 \dot{\mathrm{V}}_{\mathrm{O}_{2}}$ kinetics during $\mathrm{U} \rightarrow \mathrm{M}, \mathrm{U} \rightarrow \mathrm{VH}$, and $\mathrm{M} \rightarrow \mathrm{VH}$ exercise in boys and men.

\begin{tabular}{|c|c|c|c|c|c|c|c|}
\hline & & \multicolumn{3}{|c|}{ Boys $(n=8)$} & \multicolumn{3}{|c|}{$\operatorname{Men}(n=9)$} \\
\hline Variable & ANOVA & $\mathrm{U} \rightarrow \mathrm{M}$ & $\mathrm{U} \rightarrow \mathrm{VH}$ & $\mathrm{M} \rightarrow \mathrm{VH}$ & $\mathrm{U} \rightarrow \mathrm{M}$ & $\mathrm{U} \rightarrow \mathrm{VH}$ & $\mathrm{M} \rightarrow \mathrm{VH}$ \\
\hline$\dot{\mathrm{V}}_{\mathrm{O} 2 \mathrm{bl}}\left(\mathrm{L} \cdot \mathrm{min}^{-1}\right)$ & ${ }^{\mathrm{c}} P<0.001$ & $0.57 \pm 0.05 \dagger$ & $0.59 \pm 0.07 \dagger$ & $0.91 \pm 0.08 * \# \dagger$ & $0.83 \pm 0.12$ & $0.82 \pm 0.12$ & $1.54 \pm 0.25^{* \#}$ \\
\hline $\mathrm{TD}_{1}(\mathrm{~s})$ & ${ }^{\mathrm{b}} P=0.040$ & $12 \pm 3$ & $11 \pm 3$ & $9 \pm 2 *$ & $12 \pm 6$ & $12 \pm 6$ & $8 \pm 6 \#$ \\
\hline$\tau_{1}(\mathrm{~s})$ & ${ }^{\mathrm{ab}} P<0.001$ & $19 \pm 5 \dagger$ & $21 \pm 5 \dagger$ & $30 \pm 5^{*} \# \dagger$ & $30 \pm 5$ & $34 \pm 8$ & $49 \pm 14 * \#$ \\
\hline $\mathrm{A}_{1}\left(\mathrm{~L} \cdot \mathrm{min}^{-1}\right)$ & ${ }^{\mathrm{c}} P<0.001$ & $0.34 \pm 0.04 \uparrow$ & $0.99 \pm 0.11^{* \dagger}$ & $0.64 \pm 0.07^{* \# \dagger}$ & $0.70 \pm 0.23$ & $1.83 \pm 0.28 *$ & $1.28 \pm 0.27$ *\# \\
\hline $\mathrm{G}_{\mathrm{p}}\left(\mathrm{mL} \cdot \mathrm{min}^{-1} \cdot \mathrm{W}^{-1}\right)$ & ${ }^{\mathrm{c}} P=0.008$ & $10.6 \pm 1.1 \dagger$ & $9.5 \pm 1.0 *$ & $9.1 \pm 0.8^{*}$ & $8.5 \pm 1.4$ & $8.7 \pm 0.4$ & $9.9 \pm 1.4$ \\
\hline $\mathrm{TD}_{2}(\mathrm{~s})$ & NS & - & $172 \pm 26$ & $161 \pm 44$ & - & $155 \pm 22$ & $175 \pm 30$ \\
\hline $\mathrm{A}_{2}^{\prime}\left(\mathrm{L} \cdot \mathrm{min}^{-1}\right)$ & ${ }^{\mathrm{c}} P=0.049$ & - & $0.12 \pm 0.05 \dagger$ & $0.12 \pm 0.06 \dagger$ & - & $0.36 \pm 0.12$ & $0.24 \pm 0.07 \#$ \\
\hline Rel. $\mathrm{A}_{2}^{\prime}(\%)$ & ${ }^{\mathrm{a}} P=0.048$ & - & $11 \pm 4 \dagger$ & $15 \pm 7$ & - & $16 \pm 3$ & $16 \pm 6$ \\
\hline$\dot{\mathrm{V}}_{\mathrm{O} 2 \text { tot }}\left(\mathrm{L} \cdot \mathrm{min}^{-1}\right)$ & ${ }^{\mathrm{c}} P<0.001$ & $0.91 \pm 0.08 \dagger$ & $1.70 \pm 0.12 * \dagger$ & $1.67 \pm 0.13 * \dagger$ & $1.53 \pm 0.26$ & $3.01 \pm 0.43 *$ & $3.06 \pm 0.44^{*}$ \\
\hline $\mathrm{G}_{\text {tot }}\left(\mathrm{mL} \cdot \mathrm{min}^{-1} \cdot \mathrm{W}^{-1}\right)$ & ${ }^{\mathrm{c}} P=0.003$ & $10.6 \pm 1.1 \dagger$ & $10.7 \pm 1.0$ & $10.7 \pm 1.2$ & $8.5 \pm 1.4$ & $10.4 \pm 0.6^{*}$ & $11.8 \pm 1.0 * \#$ \\
\hline $\operatorname{MRT}(\mathrm{s})$ & ${ }^{\mathrm{c}} P=0.046$ & $31 \pm 9 \dagger$ & $40 \pm 9^{*} \dagger$ & $54 \pm 9 * \# \dagger$ & $46 \pm 9$ & $66 \pm 15^{*}$ & $83 \pm 17 * \#$ \\
\hline
\end{tabular}

Data are presented as mean $\pm \mathrm{SD}$. AVOVA, two-way repeated measures ANOVA results: ${ }^{a}$ significant main effect for age; ${ }^{\mathrm{b}}$ significant main effect for condition; ${ }^{c}$ significant age $\times$ condition interaction; NS no significant differences found $(P>0.05)$. Bonferroni adjusted paired comparisons: Significantly different from $\mathrm{U} \rightarrow \mathrm{M}$ condition: $* P<0.05$. Significantly different from $\mathrm{U} \rightarrow \mathrm{VH}$ condition: $\# P<0.05$. Significant within-condition age difference: $\uparrow P<0.05$. $\dot{\mathrm{V}}_{\mathrm{O}_{2} \mathrm{bl}}$, mean $\dot{\mathrm{V}}_{\mathrm{O}_{2}}$ during baseline pedalling; $\tau_{1}, \mathrm{TD}_{1}, \mathrm{~A}_{1}$, time constant, time delay and asymptotic amplitude of the phase II $\dot{\mathrm{V}}_{\mathrm{O}_{2}}$ response (derived from Eq. 1); TD ${ }_{2}, \mathrm{~A}_{2}{ }_{2}$, time delay and amplitude of the $\dot{\mathrm{V}}_{\mathrm{O}_{2}}$ slow component; $\mathrm{G}_{\mathrm{p}}, \mathrm{G}_{\mathrm{tot}}$, gain $\left(\Delta \dot{\mathrm{V}}_{\mathrm{O}_{2}} / \Delta \mathrm{WR}\right)$ of the primary response and at end exercise; MRT, mean response time. 
Table 2 HR kinetics during $\mathrm{U} \rightarrow \mathrm{M}, \mathrm{U} \rightarrow \mathrm{VH}$, and $\mathrm{M} \rightarrow \mathrm{VH}$ exercise in boys and men.

\begin{tabular}{|c|c|c|c|c|c|c|c|}
\hline \multirow[b]{2}{*}{ Variable } & \multirow[b]{2}{*}{ ANOVA } & \multicolumn{3}{|c|}{ Boys $(n=8)$} & \multicolumn{3}{|c|}{$\operatorname{Men}(n=9)$} \\
\hline & & $\mathrm{U} \rightarrow \mathrm{M}$ & $\mathrm{U} \rightarrow \mathrm{VH}$ & $\mathrm{M} \rightarrow \mathrm{VH}$ & $\mathrm{U} \rightarrow \mathrm{M}$ & $\mathrm{U} \rightarrow \mathrm{VH}$ & $\mathrm{M} \rightarrow \mathrm{VH}$ \\
\hline $\mathrm{HR}_{\mathrm{bl}}\left(\right.$ beats $\left.\cdot \mathrm{min}^{-1}\right)$ & $\begin{array}{l}{ }^{\mathrm{a}} P=0.010 \\
{ }^{\mathrm{b}} P<0.001\end{array}$ & $101 \pm 8 \dagger$ & $101 \pm 9 \dagger$ & $122 \pm 8 * \# \uparrow$ & $83 \pm 13$ & $85 \pm 13$ & $110 \pm 12 * \#$ \\
\hline $\operatorname{HR} \tau(\mathrm{s})$ & ${ }^{\mathrm{b}} P<0.001$ & $28 \pm 13$ & $35 \pm 8^{*}$ & $40 \pm 11^{*}$ & $32 \pm 12$ & $39 \pm 12$ & $46 \pm 16^{*}$ \\
\hline $\mathrm{HR}_{\text {tot }}$ (beats $\cdot \mathrm{min}^{-1}$ ) & $\begin{array}{l}{ }^{\mathrm{a}} P=0.043 \\
{ }^{\mathrm{b}} P<0.001\end{array}$ & $123 \pm 8 \dagger$ & $179 \pm 10^{*}$ & $179 \pm 11^{*}$ & $109 \pm 14$ & $165 \pm 16^{*}$ & $167 \pm 15^{*}$ \\
\hline$\Delta \mathrm{HR}\left(\right.$ beats $\cdot \mathrm{min}^{-1}$ ) & ${ }^{\mathrm{b}} P<0.001$ & $22 \pm 3$ & $79 \pm 8^{*}$ & $58 \pm 9^{*} \#$ & $26 \pm 8$ & $80 \pm 9 *$ & $57 \pm 5^{* \#}$ \\
\hline
\end{tabular}

Data are presented as mean $\pm \mathrm{SD}$. AVOVA, two-way repeated measures AVOVA results. See Table 1 for explanation of statistical analyses. HR $\mathrm{bl}_{\mathrm{bl}}$, mean HR during baseline pedalling; $\mathrm{HR} \tau$, time constant for $\mathrm{HR}$; $\mathrm{HR}_{\mathrm{tot}}, \mathrm{HR}$ at end-exercise; $\Delta \mathrm{HR}$, difference between $\mathrm{HR}_{\mathrm{bl}}$ and $\mathrm{HR}_{\mathrm{tot}}$. 
Fig. 1.

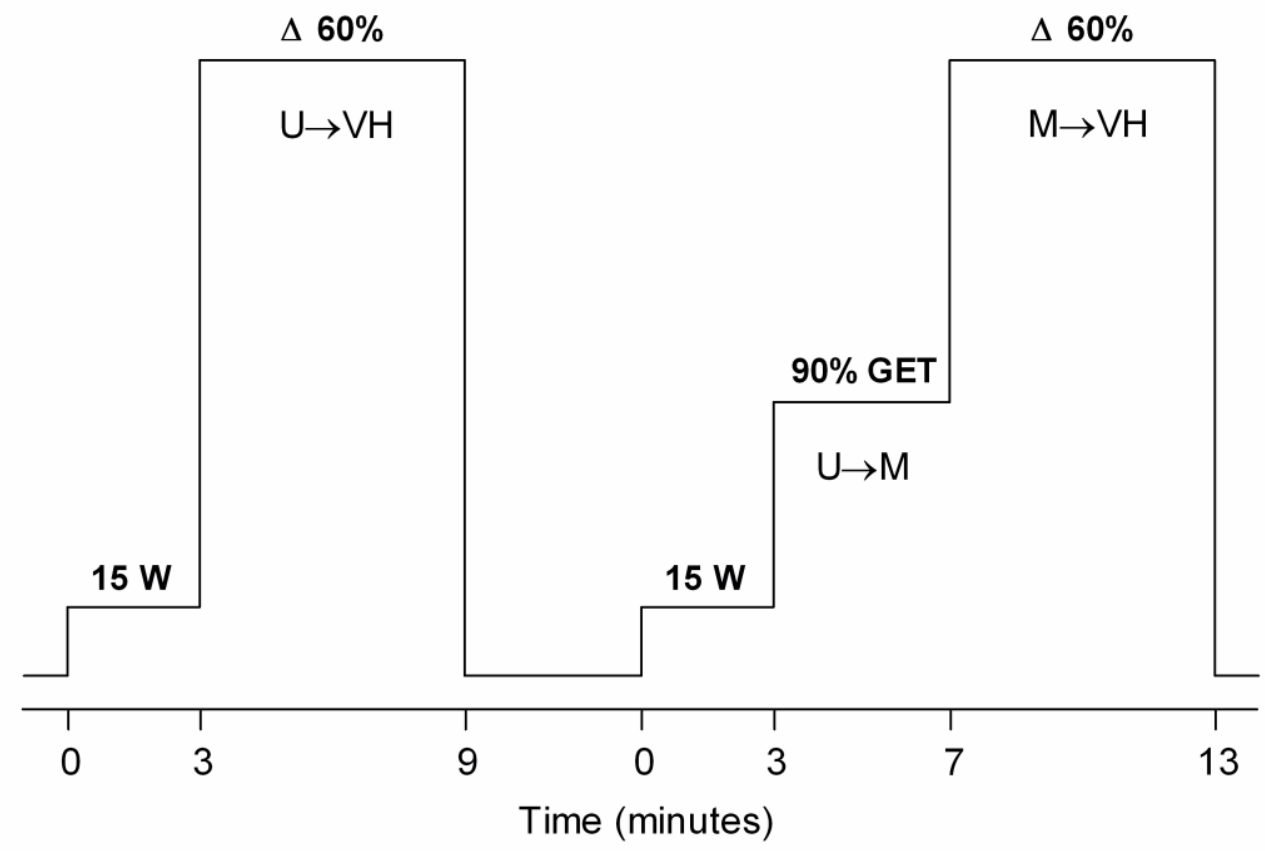


Fig. 2.
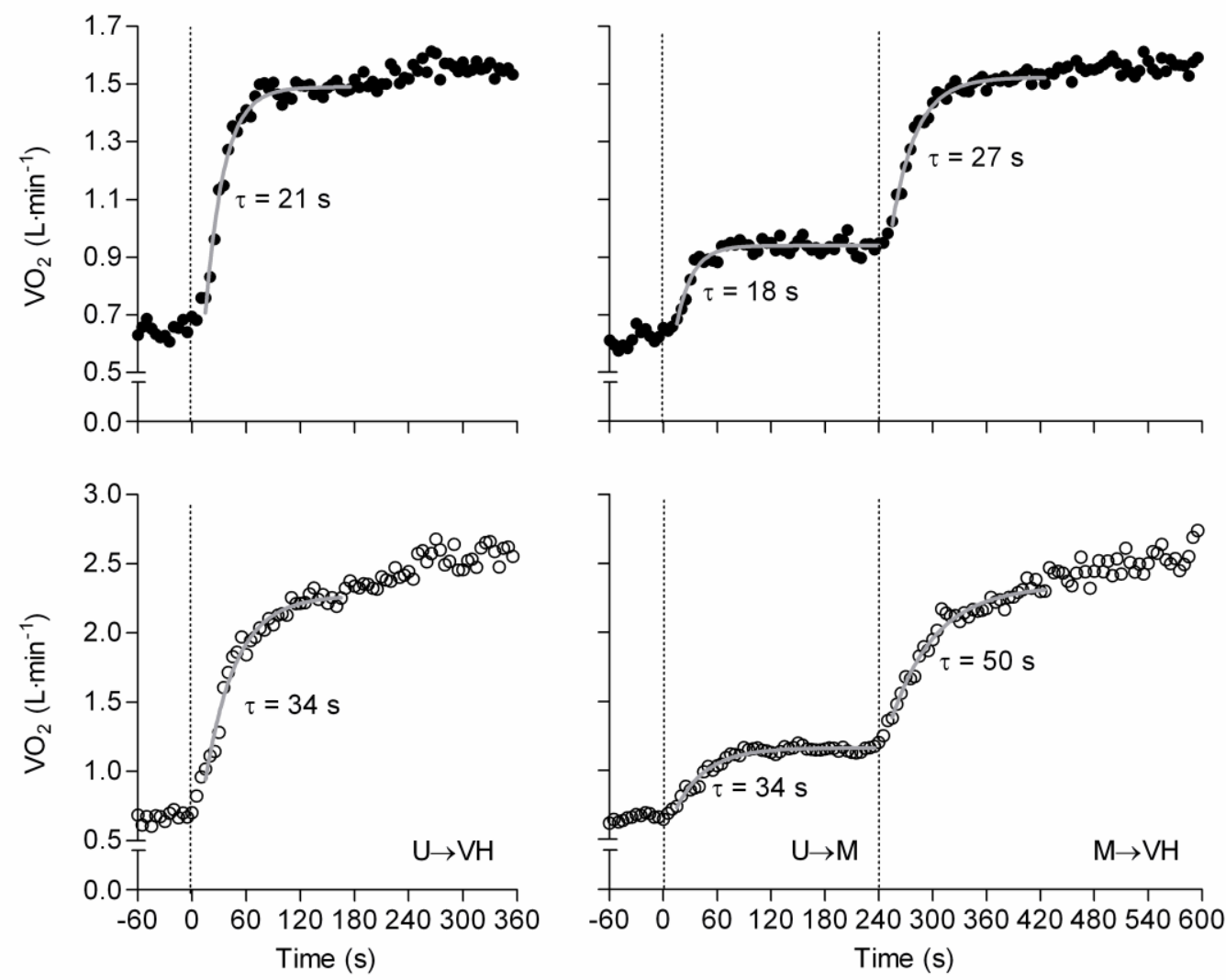
Fig. 3.
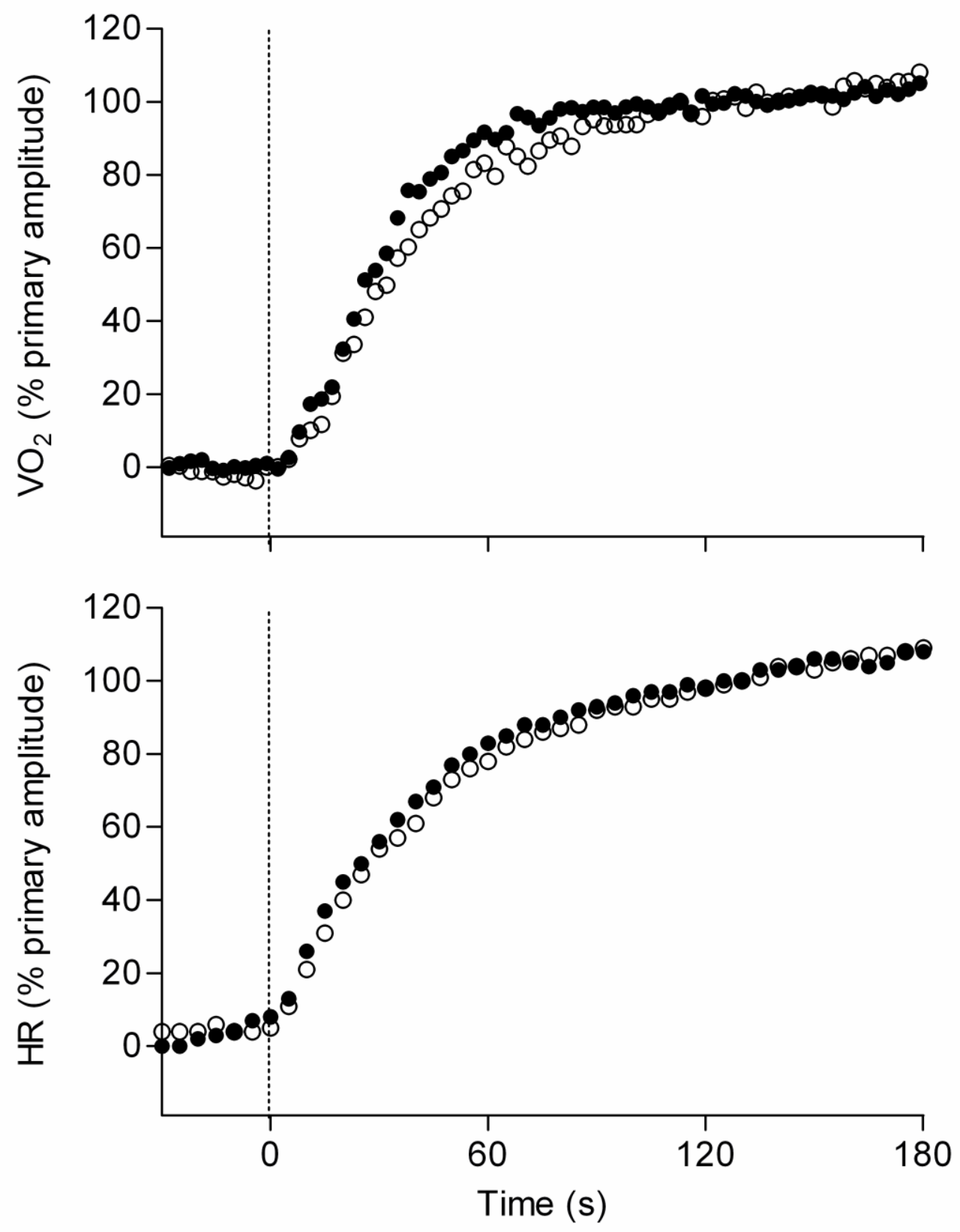
Fig. 4.

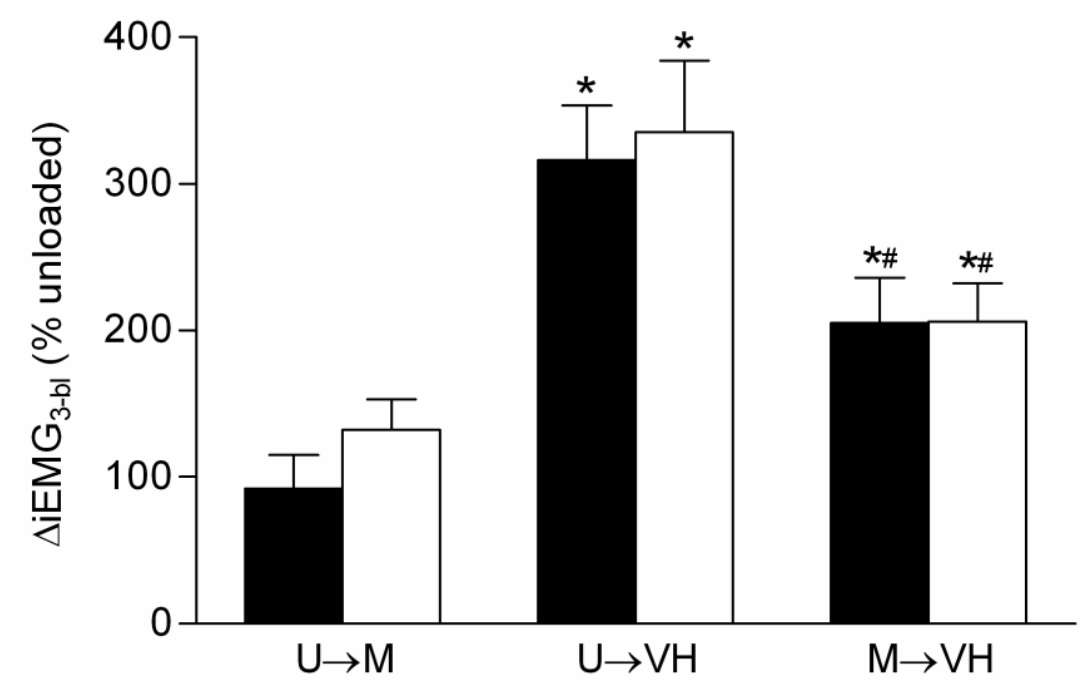

Fig. 5.

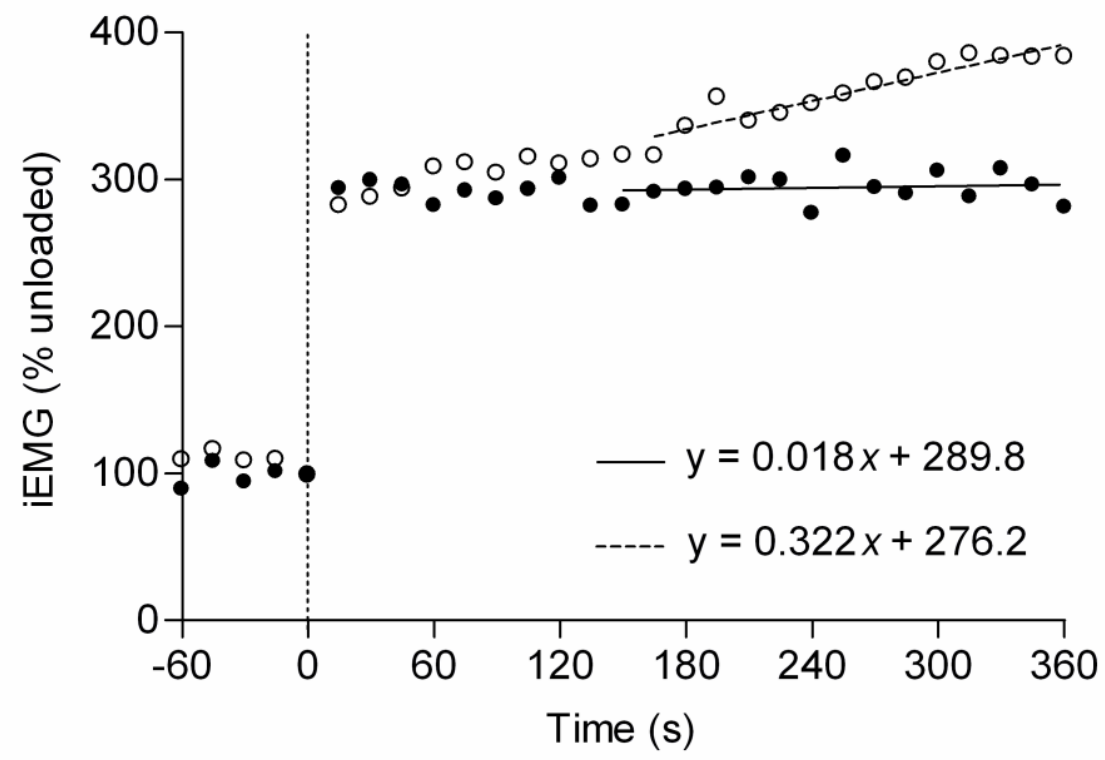

